$N 73 \cdot 20161$

\title{
$-\because$
}

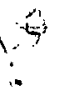

NASA TECHNICAL NOTE

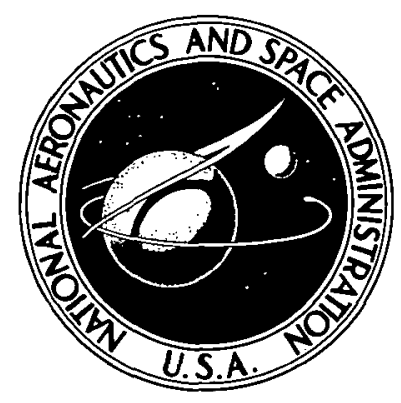

NASA TN D-7257

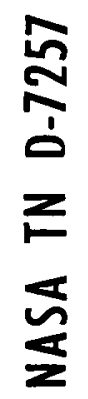
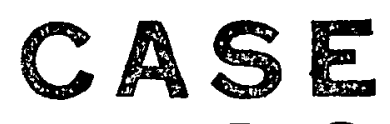

FILE

COPY

\section{A NEW TECHNIQUE FOR AUGER ANALYSIS \\ OF SURFACE SPECIES SUBJECT TO \\ ELECTRON-INDUCED DESORPTION .}

by Stephen $V$. Pepper

Lewis Research Center

Cleveland, Obio 44135

national aeronautics and space adMINISTRATION - WASHINGTON, D. C. - APRIL 1973 


\title{
A NEW TECHNIQUE FOR AUGER ANALYSIS OF SURFACE SPECIES
}

\section{SUBJECT TO ELECTRON-INDUCED DESORPTION}

\author{
by Stephen V. Pepper \\ Lewis Research Center
}

\section{SUMMARY}

A method is presented to observe surface species subject to electron-induced desorption by Auger electron spectroscopy. The surface to be examined is moved under the electron beam at constant velocity, establishing a time-independent condition and eliminating the time response of the electron spectrometer as a limiting factor. The dependence of the Auger signal on the sample velocity, incident electron current, beam diameter and desorption cross section are analyzed. It is shown that it is advantageous to analyze the moving sample with a high beam current, in contrast to the usual practice of using a low beam current to minimize desorption from a stationary sample. The method is illustrated by the analysis of a friction transfer film of PTFE, in which the fluorine is removed by electron-induced desorption. The method is relevant to surface studies in the field of lubrication and catalysis.

\section{INTRODUCTION}

The technique of Auger electron spectroscopy has been widely used to identify elements present on solid surfaces (refs. 1 to 4). This technique, however, can be a destructive method of surface analysis. The electron beam (500 to $5000 \mathrm{~V}, 1$ to $100 \mu \mathrm{amp}$ ) that ionizes the atoms in the surface region can promote desorption of surface species (refs. 5 and 6). The Auger signal of this element then decreases exponentially in time. The desorption of particular elements from the surface can thus lead to an incorrect assessment of the elemental composition of the surface by Auger electron spectroscopy.

This problem has usually been dealt with by either decreasing the incident beam current or by defocusing the beam spot while maintaining the same total electron current. The effect of these changes is to decrease the desorption rate so that there is, hopefully, negligible change in the concentration during the time necessary to obtain the 


\section{- Auger spectrum.}

It is, therefore, advantageous to work with an electron spectrometer with the fastest possible response time when detecting desorbable surface species. In this sense the cylindrical mirror analyzer (ref. 7), with its fast tracing time of approximately 100 milliseconds, is superior to the retarding potential analyzer (ref. 8) with its slower tracing time of minutes. However, the fast response time of the cylindrical mirror analyzer is useful only for detecting major Auger peaks. Detecting minor peaks requires an increase in lock-in amplifier sensitivity resulting in greater noise. Removing the noise by filtering results in a slower time response. Thus no matter which method is used, there is always the suspicion that a particular species might be desorbed before its Auger signal can be detected.

It is the purpose of this report to present a method for obtaining the Auger spectra of surface species subject to electron-induced desorption that does not depend on the time response of the electron spectrometer. The method consists of moving the sample under the electron beam at a constant velocity. Thus, fresh sample is continuously being supplied for Auger analysis, and the system reaches a steady state, allowing great flexibility in the choice of electron spectrometers and lock-in amplifier time constants. The uncertainty as to whether a species has been desorbed before its Auger signal has been detected is eliminated and the Auger analyses of desorbable and nondesorbable species are placed on a more equivalent basis.

In the next section the dependence of the Auger signal of the desorbable species on the surface velocity and electron beam current is analyzed and discussed. An experimental illustration of the technique is then given in the last section.

\section{ANALYSIS}

The basic relation that describes the depletion of a surface species under bombardment by monoenergetic electrons is

$$
N(t)=N(O) e^{-I o t / \pi r_{0}^{2}}
$$

where $N(t)$ is the surface number density of the particular species at time $t, I$ is the incident electron current in the beam spot of radius $r_{0}$, and $\sigma$ is the desorption cross section (ref. 9). Since the magnitude of the Auger signal $S$ is proportional to the surface density of the species, we have

$$
S(t)=S(0) e^{-I o t / \pi r_{0}^{2}}
$$


where $S(O)$ is the magnitude of the Auger signal in the absence of electron-induced desorption, conventionally measured as the peak-to-peak height in the $\mathrm{dN} / \mathrm{dE}$ spectrum. The exponential function in equation $(2)$ is an attenuation factor $(<1)$ that describes the loss of Auger signal due to desorption and is a function only of the dimensionless parameter $\mathrm{I} \sigma \mathrm{t} / \pi \mathrm{r}_{0}^{2}$.

We now seek a relation analogous to equation (2) for the magnitude of the Auger signal from a sample moving under the electron beam with velocity v. For this purpose consider the geometry depicted in figure 1 . The sample moves to the left under the

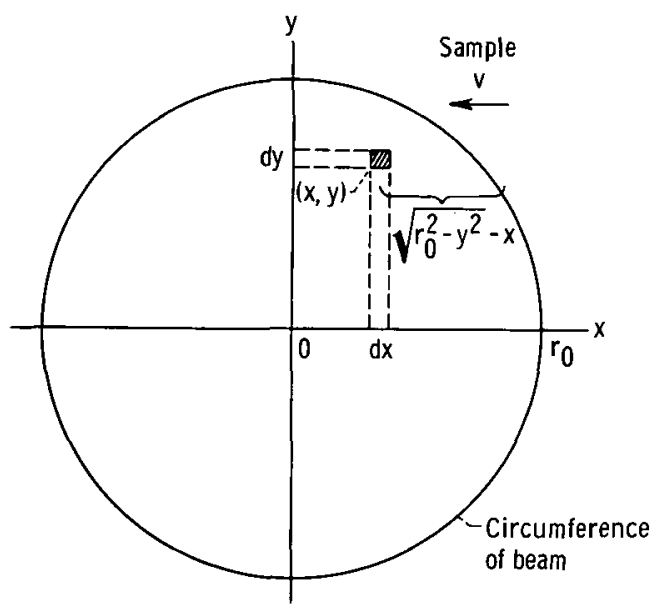

Figure 1. - Schematic of electron beam spot bombarding a surface moving to the left with velocity $v$. The spot radius is $r_{0}$, and the electron current $I$ is uniform within the spot.

electron beam of radius $r_{0}$; current $I$ is assumed to be uniform within the spot. The desorbing species is assumed to be uniformly distributed on the surface. Then the Auger signal from an elemental area of the moving sample within the beam spot is given by

$$
\mathrm{dS}=\mathrm{S}(\mathrm{O}) \exp \left[-\frac{\mathrm{I} \sigma \mathrm{t}(\mathrm{x}, \mathrm{y})}{\pi \mathrm{r}_{0}^{2}}\right] \frac{\mathrm{dxdy}}{\pi \mathrm{r}_{0}^{2}}
$$

where

$$
t(x, y)=\frac{\sqrt{r_{0}^{2}-y^{2}-x}}{v}
$$


.is the time that the element of sample at $(x, y)$ has spent under electron bombardment. The total Auger signal is then given by integration over the area under bombardment; that is,

$$
S=\int \mathrm{dS}=\frac{\mathrm{S}(\mathrm{O})}{\pi \mathrm{r}_{0}^{2}} \int_{-\mathrm{r}_{0}}^{\mathrm{r}_{0}} \iint_{-\sqrt{\mathrm{r}_{0}^{2}-\mathrm{y}^{2}}}^{\sqrt{\mathrm{r}_{0}^{2}-\mathrm{y}^{2}}} \exp \left[\frac{\mathrm{I \sigma}\left(\sqrt{\mathrm{r}_{0}^{2}-\mathrm{y}^{2}}-\mathrm{x}\right)}{\pi \mathrm{r}_{0}^{2} \mathrm{v}}\right] \mathrm{dx} d \mathrm{y}
$$

The integration over $\mathrm{x}$ is performed first. Then a change of variable for the $\mathrm{y}$ integration, $z=y / r_{0}$, gives the result

$$
\mathrm{S}=\mathrm{S}(\mathrm{O}) \frac{4}{\pi \beta}\left\{1-\int_{0}^{1} \exp \left[-\beta \sqrt{1-\mathrm{z}^{2}}\right] \mathrm{dz}\right\}
$$

where

$$
\beta=\frac{2 \mathrm{I}}{\pi \mathrm{r}_{0} \mathrm{~V}}
$$

Defining

$$
\varphi(\beta)=\frac{4}{\pi \beta}\left\{1-\int_{0}^{1} \exp \left[-\beta \sqrt{1-z^{2}}\right] d z\right\}
$$

we finally have

$$
\mathrm{S}=\mathrm{S}(\mathrm{O}) \varphi(\beta)
$$

Equation (8) is the expression for the Auger signal that is analogous to equation (2). The function $\varphi(\beta)$ is the attenuation factor that describes the loss of Auger signal due to electron-induced desorption from a moving sample and is a function only of the lumped dimensionless parameter $\beta$. The function $\varphi(\beta)$ has been numerically evaluated and is plotted as curve $A$ in figure $2(a)$.

Consider the dependence of the Auger signal on the physical parameters that make up the dimensionless parameter. $\beta$. Since the surface velocity $v$ appears in the denominator of $\beta$, the velocity dependence of $S$ is best understood in terms of $\beta^{-1}$. Thus $\varphi$ 


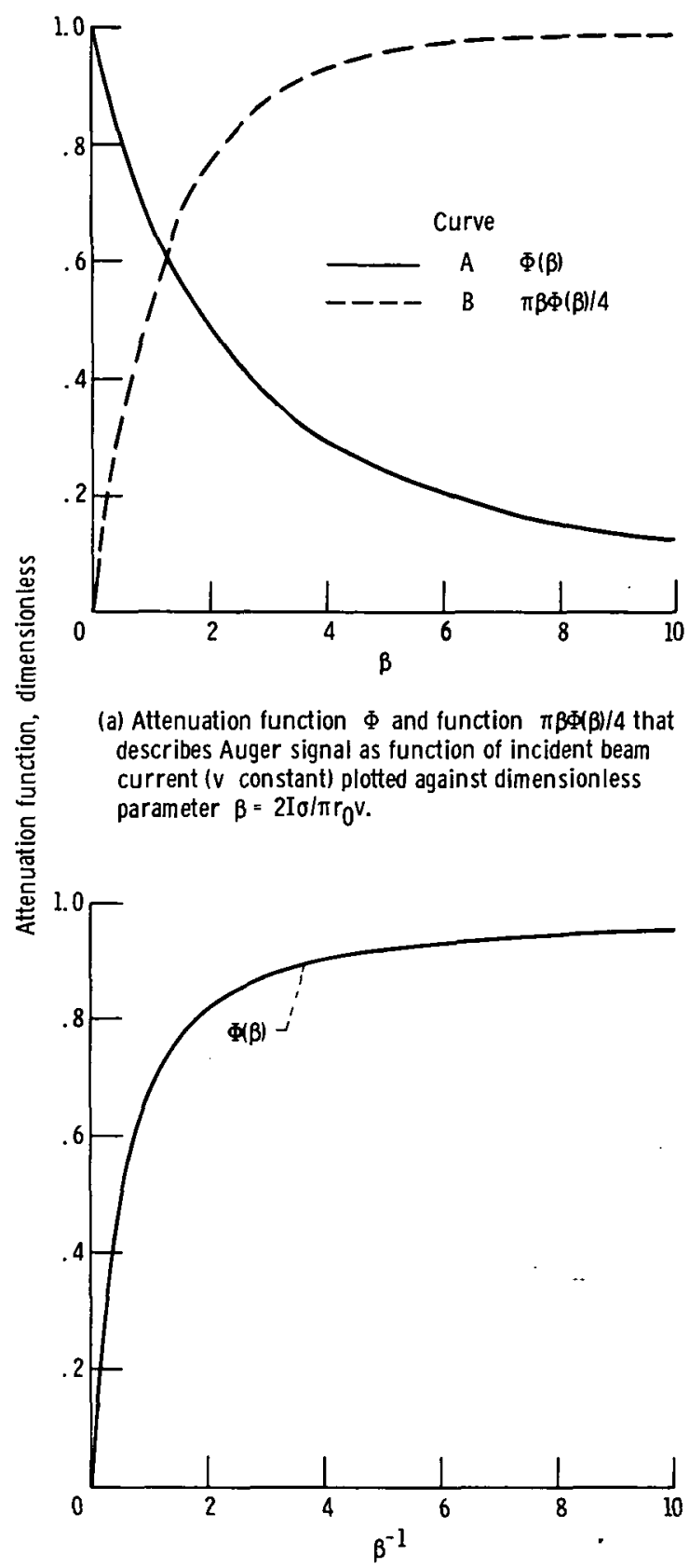

(b) Attenuation function $\Phi$ plotted against $\beta^{-1}$. This curve describes behavior of Auger signal as a function of sample velocity.

Figure 2. - Attenuation functions that describe Auger signal of electron-desorbable species on surface moving with velocity $v$.

has been plotted in figure $2(\mathrm{~b})$ as a function of $\beta^{-1}$. The signal vanishes for zero velocity since the measurements considered here are time independent and the relevant species on a stationary surface is eventually totally desorbed by the electron beam in 
accordance with equation (2). For large $\beta^{-1}$ (large v) the Auger signal asymptotically approaches the value it would have in the absence of desorption. In this velocity region, fresh sample is being fed into the beam spot at a rate high enough to maintain the average coverage in the spot close to the coverage outside the spot. It is therefore advantageous to operate with the highest practical velocity.

There are certain points of similarity between the method presented here and the usual time-dependent method. In the first place, higher desorption cross sections lead to smaller signals in both cases. Secondly, a smaller beam radius (for the same total beam current) leads to a higher desorption rate and a smaller signal. It is thus advantageous to defocus the incident beam in both methods.

However, the dependence of the signal on the incident electron beam current is quite different in the two methods. The current dependence of the Auger signal here is contained not only in $\varphi(\beta)$ but also in $\mathrm{S}(\mathrm{O})$, since the Auger signal in the absence of desorption is itself proportional to the current. The behavior of the signal with current is therefore the result of a trade-off; larger I yields a larger signal from those atoms present on the surface $(\mathrm{S}(\mathrm{O}) \sim \beta$ ), but it also means a higher desorption rate of these atoms $(\varphi(\beta))$. Since $\beta \sim \mathrm{I}$, the functional form of the dependence of the signal $\mathrm{S}(\beta)$ on current is given by $\beta \varphi(\beta)$. Multiplying by a factor $\pi / 4$ yields the function plotted as curve $B$ in figure 2(a). The curve is the Auger signal, relative to its maximum value for a given velocity, as a function of the incident current. From the monotonic increase it is seen that the increase in signal due to the increase in $\mathrm{S}(0)$ dominates the decrease in signal due to enhanced desorption. An upper limit on the Auger signal, for a given $\mathrm{v}$, arises when the species is completely desorbed before it leaves the beam spot and represents the most efficient use of the desorbable species for the purpose of Auger electron spectroscopy. Thus, in contrast to the usual practice of reducing the beam current to minimize the desorption rate, here it is advantageous to work with a high beam current to maximize the time independent Auger signal.

As a numerical example of this analysis, consider a fast desorption time of 5 seconds $\left(\mathrm{I} \sigma / \pi \mathrm{r}_{0}^{2}=0.2 \mathrm{sec}^{-1}\right)$ and $\mathrm{r}_{0}=0.05$ centimeter. Then $\beta=0.01 / \mathrm{v}$ and a velocity of 0.001 centimeter per second yields $\beta=10$ and $\varphi=0.13$ (from fig. 2(a), curve A). This reduction in signal strength is quite modest when it is remembered that this method permits the use of high sensitivity and appreciable noise filtering on the lock-in amplifier.

Finally, it should be noted that the velocity and current dependence of the signal depicted in figure 2 may be used to experimentally determine the desorption cross section $\sigma$. Such a procedure requires obtaining the signal over a wide range of either velocity or beam current and searching for the best fit of the relevant curve to the data. Such a procedure would be analogous to plotting the time-dependent signal from a stationary surface and using equation (2) to obtain $\sigma$. However, just as the time response 
of the electron spectrometer imposes a limitation on the use of equation (2), there may be practical difficulties to the use of the velocity or current dependence of the signal for this purpose. For example, increasing the beam current may result in an enlarged beam spot, leading to a signal that increases instead of saturating as in curve $B$, figure 2(a). The particular experimental situation will no doubt dictate the particular method to be used, and therefore no general procedure can be given.

\section{ILLUSTRATION}

An illustration of the essential features of the method described herein is provided by the examination of a mechanically applied thin lubricant film of polytetrafluoroethylene (PTFE) on a tungsten surface. It has recently been shown that when PTFE slides on a surface, a transfer film only a few monolayers thick is developed on the surface (refs. 10 and 11). Such a film was developed here by sliding the tip of a PTFE bullet (radius, $0.476 \mathrm{~cm}$ ) on a sputter-cleaned tungsten disk in vacuum at a load of $100 \mathrm{grams}$ and a velocity of 0.1 centimeter per second (ref. 11). The experimental arrangement is depicted in figure 3.

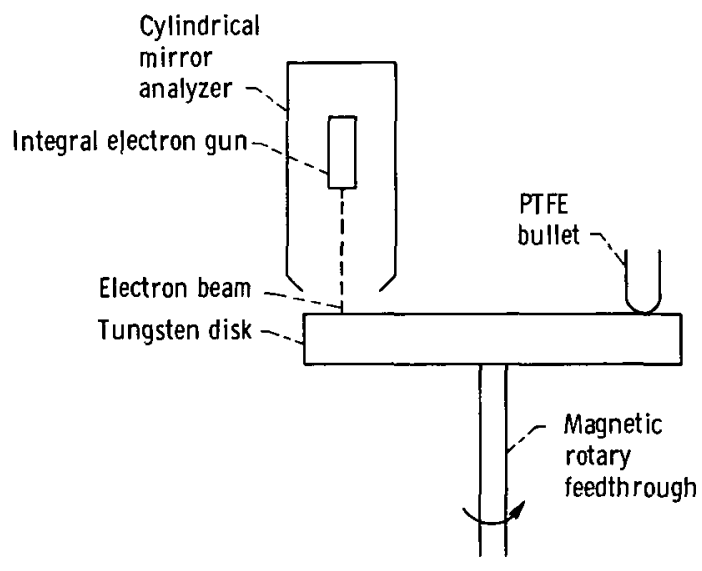

Figure 3. - Experimental arrangement used to apply PTFE transfer film to disk in vacuum. PTFE bullet was raised from disk after film was applied.

The Auger spectra from this surface are presented in figure 4. In figure 4(a) the spectrum from the stationary surface under bombardment by the 2000-volt, 10 microampere beam for 2 minutes indicates the major surface species are tungsten and carbon from the PTFE. Fluorine is present only as a very minor peak. The Auger spectrum from the moving surface presented in figure $4(\mathrm{~b})$ indicates the presence of 


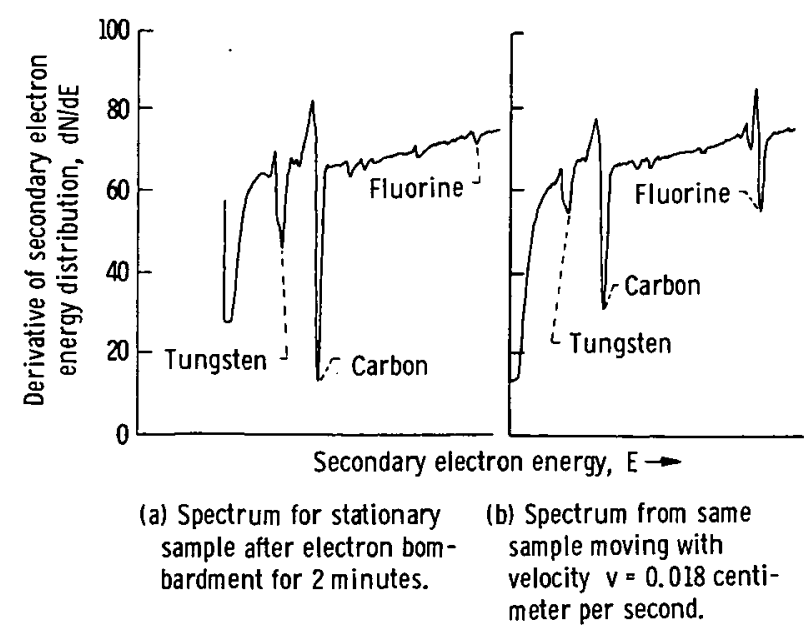

Figure 4. - Auger spectrum of PTFE transfer film on tungsten surface. Electron beam current, 10 microamperes; beam voltage, 2000 volts.

much more fluorine on the surface than is indicated by figure 4(a). Note also that the size of the tungsten and carbon peaks from the moving surface are smaller than those from the stationary surface, indicating that the fluorine in the PTFE chain attenuates the Auger electrons of the tungsten and carbon atoms. Thus all the major peaks in Auger spectrum are affected by electron-induced desorption of the fluorine and the convenience of exhibiting the entire Auger spectrum on a time-independent basis is apparent.

The velocity dependence of the magnitude of the fluorine Auger signal is presented in figure 5. There are three main features to this data. First, note that the signal does not vanish for zero velocity indicating that some of the fluorine is not subject to electron-induced desorption. Secondly, the signal increases rapidly for small velocities and then starts to level off. The general behavior is thus similar to that depicted in figure $2(b)$ for the velocity dependence of the signal. Finally, note that, instead of reaching

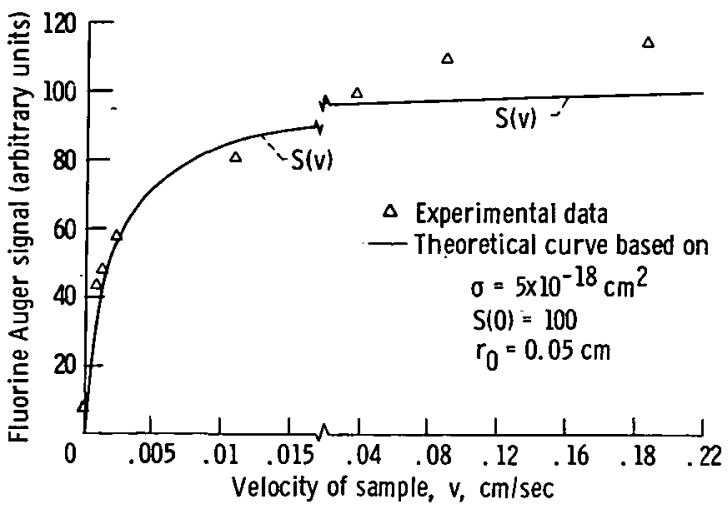

Figure 5. - Fluorine Auger signal plotted against velocity of sample. Electron beam current, 10 microamperes. 
a maximum and leveling off, the fluorine signal is still increasing for the largest velocity used.

Thus the results in figure 5 indicate that the fluorine in the film exhibits a wide range of binding states as far as electron-induced desorption is concerned and this is probably a consequence of the multilayer structure of this mechanically applied film. The fluorine in the interior of the film adjacent to the substrate has a high probability of reforming the bond broken by the incident electrons and is thus subject to desorption at a very low rate. This fluorine may be detected by Auger spectrometers that have the poorest time response such as the retarding potential analyzer. The bulk of the fluorine in the film has approximately the same cross section for electron-induced desorption since the velocity dependence is generally in accord with that predicted on the basis of a single desorption cross section (fig. 2(b)). The desorption time for this fluorine is about 40 seconds and may be detected on a stationary surface with a cylindrical mirror analyzer, but not with a retarding potential analyzer with any accuracy. A choice of $\sigma=5 \times 10^{-18}$ and $S(O)=100$ in the theoretical expression for the velocity dependence provides a curve in fair accord with the data in figure 5. This cross section is in good agreement with that obtained from the time dependence of the Auger signal from a stationary surface (ref. 11). This is also a physically reasonable value for atoms in such a multilayer structure since it is larger than that for chemisorbed species on metals $\left(\sigma<10^{-18} \mathrm{~cm}^{2}\right)$ and smaller than the ionization cross section for free atoms $\left(\sim 10^{-16} \mathrm{~cm}^{2}\right)$ (ref. 12).

Since the theoretical curve based on $\sigma=5 \times 10^{-18}$ square centimeters is essentially flat for $v>0.04$ centimeter per second, the fact that the signal is still increasing for these velocities implies that there is some fluorine in the film with desorption cross section much greater than $5 \times 10^{-18}$ square centimeters. This fluorine is probably at the PTFE-vacuum interface and has a cross section approaching the ionization cross section for atoms in the free state. Detection of such species in the usual way on a stationary surface is a difficult, if not impossible, task especially if the species is a minor constituent of the surface. In contrast, the technique presented here relaxes the stringent requirements on the time response of the spectrometer system and makes the detection of species with such high desorption cross sections a rather straightforward task.

\section{CONCLUDING REMARKS}

It has been shown here that it is possible to observe the Auger spectra of electrondesorbable surface species on a time-independent basis by moving the surface at a constant velocity with respect to the electron beam. A uniform coverage of the desorbable 
species in the region probed by the electron beam is required and the technique is timeindependent to the extent that the Auger spectrum can be obtained before this region of the sample is traversed. The technique presented here will be most useful in those situations for which the rate of electron-induced desorption is greatest. High desorption rates are expected for those species in least electronic contact with the substrate and this is the case for fluorine in a PTFE film. In addition, the fluorine has only a single valence bond to the polymer chain. High electron-induced desorption rates are thus expected for polymeric lubricant films. In this connection, it has recently been pointed out that the weakly bound surface species most active in catalysis are also sensitive to electron-induced desorption (ref. 9). The technique presented here should thus find application in the investigation of both polymeric lubricant films and catalytic processes by Auger electron spectroscopy.

The experimental arrangement used here (fig. 3) moves the sample with respect to the stationary beam, but there is also the possiblity of moving the electron beam over the stationary sample. However, the amount of sample that can be traversed with such an arrangement is limited, due to the necessity of having the source of the Auger electrons quite close to the axis of the electron spectrometer. Thus most effective use of the technique presented here requies a motor-driven sample holder and the use of somewhat extended samples.

Finally we point out that the technique presented here for dealing with electroninduced desorption is a rather general way of alleviating the effects of any undesirable phenomena associated with the electron beam. The charging of insulators (especially under normal incidence), heating of the sample, and electron-induced adsorption (ref. 13) all occur within the beam spot. Moving fresh sample into the beam tends to reduce the degree to which these processes occur and thus provide a more desirable surface for Auger analysis.

Lewis Research Center,

National Aeronautics and Space Administration, Cleveland, Ohio, February 2, 1973, 502-01. 


\section{APPENDIX - SYMBOLS}

I electron beam current, electrons/sec

$\mathrm{N}$ surface number density of desorbable species, $\mathrm{cm}^{-2}$

$r_{0} \quad$ electron beam radius, $\mathrm{cm}$

S Auger signal, arbitrary units

$\mathrm{S}(\mathrm{O}) \quad$ Auger signal in the absence of electron-induced desorption

$t$ time that the sample has spent under electron beam, sec

$\mathrm{V}$ beam voltage, $\mathrm{V}$

$v$ velocity of sample, $\mathrm{cm} / \mathrm{sec}$

$\beta \quad 2 \mathrm{I} \sigma / \pi \mathrm{r}_{0} \mathrm{v}$, dimensionless

$\sigma \quad$ cross section for electron-induced desorption

$\varphi$ function that describes the attenuation of Auger signal due to electron-induced desorption from moving sample, dimensionless 


\section{REFERENCES}

1. Weber, R. E. ; and Peria, W. T.: Use of LEED Apparatus for the Detection and Identification of Surface Contaminents. J. Appl. Phys., vol. 38, no. 11, Oct. 1967, pp. 4355-4358.

2. Harris, L. A.: Analysis of Materials by Electron-Excited Auger Electrons. J. Appl. Phys., vol. 39, no. 3, Feb. 15, 1968, pp. 1419-1427.

3. Harris, R. A. : Some Observations of Surface Segregation by Auger Electron Emission. J. Appl. Phys., vol. 39, no. 3, Feb. 15, 1968, pp. 1428-1431.

4. Chang, Chuan C.: Auger Electron Spectroscopy. Surface Sci., vol. 25, no. 1, Mar. 1971, pp. 53-79.

5. Florio, J. V.; and Robertson, W. D. : Chlorine Reactions on the Si(III) Surface. Surface Sci., vol. 18, 1969, pp. 398-427.

6. Tracy, J. C. ; and Palmberg, P. W. : Structural Influences on Adsorbate Binding Energy. I. Carbon Monoxide on (100) Palladium. J. Chem. Phys., vol. 51, no. 11, Dec. 1, 1969, pp. 4852-4862.

7. Palmberg, P. W.; Bohn, G. K. ; and Tracy, J. C. : High Sensitivity Auger Electron Spectrometer. Appl. Phys. Letters, vol. 15, no. 8, Oct. 15, 1969, pp. 254-255.

8. Taylor, N. J.: Resolution and Sensitivity Considerations of an Auger Electron Spectrometer Based on Display LEED Optics. Rev. Sci. Instr., vol. 40, no. 6, June 1969, pp. 792-804.

9. Madey, Theodore E.; and Yates, John T., Jr.: Electron-Stimulated Desorption as a Tool for Studies of Chemisorption: A Review. J. Vac. Sci. Tech., vol. 8, no. 4, 1971, pp. 525-555.

10. Pooley, Christine M.; and Tabor, D.: Friction and Molecular Structure: The Behaviour of Some Thermoplastics. Proc. Roy. Soc. (London) Ser. A, vol. 329, no. 1578, Aug. 22, 1972, pp. 251-274.

11. Pepper, Stephen V.; and Buckley, Donald H.: Adhesion and Transfer of Polytetrafluoroethylene to Metals Studied by Auger Emission Spectroscopy. NASA TN D-6983, 1972.

12. Kieffer, L. J.; and Dunn, Gordon H.: Electron Impact Ionization Cross-Section Data for Atoms, Atomic Ions, and Diatomic Molecules: I. Experimental Data. Rev. Mod. Phys., vol. 38, no. 1, Jan. 1966, pp. 1-35.

13. Coad, J. P.; Bishop, H. E.; and Rivière, J. C.: Electron-Beam Assisted Adsorption on the Si(III) Surface. Surface Sci., vol. 21, 1970, pp. 253-264. 


\begin{tabular}{|c|c|c|c|}
\hline $\begin{array}{l}\text { 1. Report No. } \\
\text { NASA TN D-7257 }\end{array}$ & 2. Government Accession No. & \multicolumn{2}{|c|}{ 3. Recipient's Catalog No. } \\
\hline \multirow{2}{*}{\multicolumn{2}{|c|}{$\begin{array}{l}\text { 4. Title and Subtitle } \\
\text { A NEW TECHNIQUE FOR AUGER ANALYSIS OF SURFACE } \\
\text { SPECIES SUBJECT TO ELECTRON-INDUCED DESORPTION }\end{array}$}} & \multicolumn{2}{|l|}{$\begin{array}{l}\text { 5. Report Date } \\
\text { April } 1973\end{array}$} \\
\hline & & \multicolumn{2}{|c|}{ 6. Performing Organization Code } \\
\hline $\begin{array}{l}\text { 7. Author(s) } \\
\text { Stephen V. Pepper }\end{array}$ & & \multicolumn{2}{|c|}{$\begin{array}{l}\text { 8. Performing Organization Report No. } \\
\text { E-7206 }\end{array}$} \\
\hline \multirow{3}{*}{\multicolumn{2}{|c|}{$\begin{array}{l}\text { 9. Performing Organization Name and Address } \\
\text { Lewis Research Center } \\
\text { National Aeronautics and Space Administration } \\
\text { Cleveland, Ohio } 44135\end{array}$}} & \multicolumn{2}{|l|}{$\begin{array}{l}\text { 10. Work Unit No. } \\
502-01\end{array}$} \\
\hline & & \multicolumn{2}{|c|}{ 11. Contract or Grant No. } \\
\hline & & \multicolumn{2}{|c|}{$\begin{array}{l}\text { 13. Type of Report and Period Covered } \\
\text { Technical Note }\end{array}$} \\
\hline \multicolumn{2}{|c|}{$\begin{array}{l}\text { 12. Sponsoring Agency Name and Address } \\
\text { National Aeronautics and Space Administration } \\
\text { Washington, D. C. } 20546\end{array}$} & \multicolumn{2}{|c|}{ 14. Sponsoring Agency Code } \\
\hline \multicolumn{4}{|l|}{ 15. Supplementary Notes } \\
\hline \multicolumn{4}{|c|}{$\begin{array}{l}\text { 16. Abstract } \\
\text { A method is presented to observe surface species subject to electron-induced desorption by } \\
\text { Auger electron spectroscopy. The surface to be examined is moved under the electron beam } \\
\text { at constant velocity, establishing a time-independent condition and eliminating the time response } \\
\text { of the electron spectrometer as a limiting factor. The dependence of the Auger signal on the } \\
\text { surface velocity, incident electron current, beam diameter, and desorption cross section are } \\
\text { analyzed. The method is illustrated by the Auger analysis of PTFE, in which the fluorine is } \\
\text { removed by electron-induced desorption. }\end{array}$} \\
\hline $\begin{array}{l}\text { 17. Key Words (Suggested by Author(s)) } \\
\text { Auger electron spectroscopy } \\
\text { Electron-induced desorption } \\
\text { Surface analysis } \\
\text { Polymers }\end{array}$ & $\begin{array}{l}\text { 18. Distribution Sta } \\
\text { Unclassifi }\end{array}$ & unlimited & \\
\hline $\begin{array}{r}\text { 19. Security Classif. (of this report) } \\
\text { Unclassified }\end{array}$ & $\begin{array}{l}\text { 20. Security Classif. (of this page) } \\
\text { Unclassified }\end{array}$ & \begin{tabular}{|c|} 
21. No. of Pages \\
13
\end{tabular} & $\begin{array}{l}\text { 22. Price } \\
\$ 3.00\end{array}$ \\
\hline
\end{tabular}

${ }^{*}$ For sale by the National Technical Information Service, Springfield, Virginia 22151 
"The aeronautical and space activities of the United States shall be conducted so as to contribute ... to the expansion of buman knowledge of phenomena in the atmosphere and space. The Administration shall provide for the widest practicable and appropriate dissemination of information concerning its activities and the results thereof."

\section{NASA SCIENTIFIC AND TECHNICAL PUBLICATIONS}

TECHNICAL REPORTS: Scientific and technical information considered important, complete, and a lasting contribution to existing knowledge.

TECHNICAL NOTES: Information less broad in scope but nevertheless of importance as a contribution to existing knowledge.

TECHNICAL MEMORANDUMS:

Information receiving limited distribution because of preliminary data, security classification, or other reasons. Also includes conference proceedings with either limited or unlimited distribution.

CONTRACTOR REPORTS: Scientific and technical information generated under a NASA contract or grant and considered an important contribution to existing knowledge.
TECHNICAL TRANSLATIONS: Information published in a foreign language considered to merit NASA distribution in English.

SPECIAL PUBLICATIONS: Information derived from or of value to NASA activities. Publications include final reports of major projects, monographs, data compilations, handbooks, sourcebooks, and special bibliographies.

\section{TECHNOLOGY UTILIZATION}

PUBLICATIONS: Information on technology used by NASA that may be of particular interest in commercial and other non-aerospace applications. Publications include Tech Briefs, Technology Utilization Reports and Technology Surveys.

Defails on the availability of these publications may be obtained from:

SCIENTIFIC AND TECHNICAL INFORMATION OFFICE 